\title{
Redox Property of Cu-Fe Based Oxygen Carriers Promoted with $\mathrm{MnO}_{2}$
}

\author{
Yong Han Jeong ${ }^{1}$, No-Kuk Park ${ }^{1}$, Tae Jin Lee ${ }^{1}$, Si Ok Ryu ${ }^{1}$, Misook Kang ${ }^{2}$, Jeom-In Baek ${ }^{3}$, Ho-Jung Ryu ${ }^{4}$ \\ ${ }^{1}$ School of Chemical Engineering, Yeungnam University \\ 280, Daehak-Ro, Gyeongsan, Korea \\ madmovie0@gmail.com; nokukpark@ynu.ac.kr; soryu@ynu.ac.kr; tjlee@ynu.ac.kr \\ ${ }^{2}$ School of Chemistry, Yeungnam University \\ mskang@ynu.ac.kr \\ ${ }^{3}$ Korea Electric Power Research Institute \\ 105, Munji-Ro, Yuseong-Gu, Daejeon, Korea \\ jibaek@kepco.co.kr \\ ${ }^{4}$ Korea Institute Energy Research \\ 152, Gajeong-Ro, Yuseong-Gu, Daejeon, Korea \\ hjryu@ kier.re.kr
}

\section{Extended Abstract}

Carbon dioxide $\left(\mathrm{CO}_{2}\right)$ is considered as a major component of global warming. Carbon capture and storage is recognized as one of the major options to mitigate $\mathrm{CO}_{2}$ emission. In this case, Chemical-looping combustion (CLC) is promising technology that provides inherent $\mathrm{CO}_{2}$ separation without a capture facility [1,2]. Cu-Fe based mixed metal oxides as oxygen carriers were prepared by a chemical co-precipitation method. Iron(III) nitrate and copper(II) nitrate were used as the precursors. After drying for $12 \mathrm{~h}$, the precipitates were calcined at $900{ }^{\circ} \mathrm{C}, 1000{ }^{\circ} \mathrm{C}$ and $1100{ }^{\circ} \mathrm{C}$, respectively. The surface formation of the $\mathrm{Cu}-\mathrm{Fe}$ based oxygen carriers was investigated by scanning electron microscopy(SEM) method, and the crystal structure and crystallinity were analysed by X-ray diffraction (XRD) method. The crystal structure of each samples was confirmed in XRD with the spinel structure of $\mathrm{CuFe}_{2} \mathrm{O}_{4}$ and their crystallinity increased with increase of calcination temperature due to crystal growth. Crystallite $\mathrm{CuFe}_{2} \mathrm{O}_{4}$ spinel formed when the sample was calcined over $1000{ }^{\circ} \mathrm{C}$. On the other hand, a small amount of copper was melted and migrated to the outside of sample particles. The oxygen transfer capacity of the $\mathrm{Cu}-\mathrm{Fe}$ based mixed oxide was approximately $10 \%$, and increased weakly with increase of crystallinity. A $3^{\text {rd }}$ transition metal component should be added to generate of crystal defects site in the lattice structure of the oxygen carrier. The stability of the $\mathrm{Cu}-\mathrm{Fe}$ based mixed metal oxides was enhanced with manganese oxide used as the additive material. To improve the oxidation rate of $\mathrm{Cu}-\mathrm{Fe}$ based mixed metal oxide sample, $\mathrm{Mn}$ was added as the additive and TGA tests were carried out under the same conditions for the investigation of the oxygen transfer capacity as the oxygen carrier. Manganese nitrate was used as the precursor material for the addition of Mn on co-precipitation. The weight of $\mathrm{Cu}-\mathrm{Fe}-\mathrm{Mn}$ sample was reduced approximately 5.7-10\% during $15 \mathrm{~min}$ of reduction process, the changing weight by reduction significant increased from 1 cycle to 3 cycle, and was continuously maintained after 4 cycle. The oxidation rate of reduced sample was not changed for 10-cycles of reduction and oxidation processes. On the other hand, the morphology of $\mathrm{Cu}-\mathrm{Fe}-\mathrm{Mn}$ sample was observed before reaction and after 10-cycle tests by SEM. Although the surface morphology of $\mathrm{Cu}-\mathrm{Fe}-\mathrm{Mn}$ sample was changed after 10-cycle tests, the migration and melting of $\mathrm{Cu}$ was not observed. However, the surface morphology of $\mathrm{Cu}-\mathrm{Fe}$ sample was changed after 10 cycle tests and the migration and melting of $\mathrm{Cu}$ produce during reduction process was observed too. It was concluded that manganese oxides have redox property as the oxygen carrier for chemical looping combustion, and is suitable material as the additive for high stability of $\mathrm{Cu}-\mathrm{Fe}$ mixed metal oxides to prevent the migration of $\mathrm{Cu}$.

\section{References}

[1] J. I. Baek, S. R. Yang, T. H. Eom, J. B. Lee, and C. K. Ryu, "Effect of MgO addition on the physical properties and reactivity of the spray-dried oxygen carriers prepared with a high content of $\mathrm{NiO}$ and $\mathrm{Al}_{2} \mathrm{O}_{3}$," Fuel., vol. 144, pp 317326,2015 
[2] A. Hedayati, A. M. Azad, M. Ryden, H. Leion, and T. Mattison, "Ecaluation of Novel Ceria-Supported Metal Oxides as Oxygen Carrier for Chemical-Looping Combustion," Ind. Eng. Chem. Res., vol. 51, no. 39, pp 12796-12806, 2012 